\title{
Exploring the Origins of the Normal Prostate and Prostate Cancer Stem Cell
}

\author{
Susan Kasper
}

Published online: 4 September 2008

(C) Humana Press 2008

There are two typographical errors on the third page of the published manuscript.

In the first column, in paragraph 2, in the sentence "Distal epithelium consisted of tall columnar cells which could undergo mitosis, intermediate epithelium were tall columnar, secretory cells and distal epithelial was composed of low columnar or cuboidal cells which stained for cathepsin $\mathrm{D}$, a marker for apoptosis," where is written "distal epithelial" should instead read "proximal epithelium."

In the first paragraph of the section "Origin of the Prostate Stem Cell," in the sentence "It is generally thought that PCPs do not express AR or p63," where is written PCPs should instead read PSCs.

The online version of the original article can be found at http://dx.doi. org/10.1007/s12015-008-9033-1.

S. Kasper $(\bowtie)$

Department of Urologic Surgery, A-1302 Medical Center North,

Vanderbilt University Medical Center,

116121 st Avenue South,

Nashville, TN 37232-2765, USA

e-mail: susan.kasper@vanderbilt.edu 